\title{
The large electron positron storage ring preinjector vacuum systems: Design and performance
}

\author{
M. Bourgeois, M. Brouet, J. C. Godot, F. Malthouse, and A. Poncet \\ CERN, 1211, Geneva 23, Switzerland \\ M. Roch \\ LAL, Orsay, 91405 Orsay Cedex, France
}

(Received 25 September 1986; accepted 1 December 1986)

\begin{abstract}
The large electron positron storage ring (LEP) preinjector will provide the particles to be stored in the LEP. It is composed of a high-intensity linear accelerator (linac) providing $200-\mathrm{MeV}$ electrons for the production of positrons, a low-intensity linac (LIL) for the acceleration of electrons and positrons to $600 \mathrm{MeV}$ (LIL), and an electron positron accumulator (EPA) ring to collect dense bunches of electrons and positrons at $600 \mathrm{MeV}$ (EPA). The LIL rf accelerating cavities and waveguides are typical of severely conductance limited vacuum systems with high rf induced gas loads, in which a low hydrocarbon free residual pressure has to be maintained ( $5 \times 10^{-8} \mathrm{mbar}$ ). For the EPA ring, subjected to synchrotron radiation induced gas desorption, considerations of beam lifetime require a base pressure in the $10^{-9}$ mbar range, achievable without in situ bakeout in the shortest possible time. The design features with particular emphasis on conceptual choices, cleanliness and special treatments, new hardware, low outgassing achievements, as well as cost and initial performances of these vacuum systems are presented.
\end{abstract}

\section{INTRODUCTION}

CERN is constructing a large electron positron storage ring (LEP) for colliding beam experiments near its present site. ${ }^{1}$ As parts of the injector chain two electron linacs [LEP injector linacs (LIL)] have been built which deliver bunches of electrons and positrons into a $600-\mathrm{MeV}$ accumulator and damping ring [electron positron accumulator (EPA)], where the particles will transit during $1-15 \mathrm{~s}$ before further future acceleration into the proton synchrotron (PS) and super proton synchrotron (SPS), before final delivery to LEP. LIL and EPA are new machines in the PS accelerator complex (Fig. 1). Their construction started in 1983 and they are actually in a running-in stage, with electron beams of 500-MeV energy.

\section{THE LIL VACUUM SYSTEM}

The 200-MeV high-intensity electron linac (linac V) followed by the $600-\mathrm{MeV}$ electron positron linac (W) of a total length of $101 \mathrm{~m}$ (Fig. 2) are composed of 16 nearly identical 4.8-m-long sections. Each section contains, in a cylindrical stainless-steel tube, a traveling wave structure composed of a string of $137 \mathrm{~S}$ band copper cavities. The rf power of up to $100 \mathrm{MW}$ over $1 \mu \mathrm{s}$ from each klystron located in a gallery above the linacs is fed to groups of two or four sections via about $350 \mathrm{~m}$ (in total) of evacuated $72 \times 34 \mathrm{~mm}$ rectangular waveguides, with no $\mathrm{rf}$ window to separate their respective vacuum. All metal sector valves mounted in the intersections are used to isolate each set of klystron, waveguides, and associated cavities. The two preinjectors (linacs $V$ and $W$ ) with their associated equipment (electron guns, buncher, and converter) are isolated by valves and form specific subsystems.

The nominal pressure range of $<10^{--7}$ mbar achievable in less than two days of pumping has been chosen on the basis of previous experience with electron linacs (large rf power transmission without breakdown, electron scatter, and mul- tipactor on klystron windows). This pressure range is ideally suited for low cost and maintenance-free sputter-ion pumps, the advantages of which barely need to be further demonstrated for accelerator applications. The use of triode sputter-ion pumps in combination with turbonolecular pumping stations, which are usually isolated from the high-vacuum system after roughing from atmospheric pressure down to $10^{-4}-10^{-5}$ mbar, warrants a hydrocarbon-free vacuum, and has little principle alternative from the cost point of view. The widespread success of such pumping systems has created the market conditions justifying continnous developments towards improved reliability, better pumping characteristics, and at ever lower prices. Therefore, the vacuum designer is mainly left with such problems as how to optimize the number of pumps, power supplies, and gauges; devise proper cleaning and manufacturing methods, and provoke enlarged competitive tendering between commercial firms in order to minimize the cost of the system. Optimizing the number and size of pumps for a given performance and anticipated gas load for minimum cost is a univocal problem of upmost importance for severely conductance limited vacuum systems such as the LIL cavities and waveguides; the required number of pumps is necessarily large and the overall cost rises faster with the number of pumps than with the pumps nominal pumping speed.

For the LIL waveguides a $30 \mathrm{l} / \mathrm{s}$ triode sputter-ion pump ( StarCell, trademark by Varian) has been chosen based on the low price obtained on large quantities for the LEP machine, following competitive tendering. The 4.8-m-long accelerating sections are pumped by $1001 / \mathrm{s}$ triode sputter-ion pumps piaced at each extremity. Determination of intervals between pumps has been performed by optimization of the complete pressure profile over the whole waveguide network and accelerating section subsystem, using a computer program based on measured values of outgassing rates versus pumping time. ${ }^{2}$ 


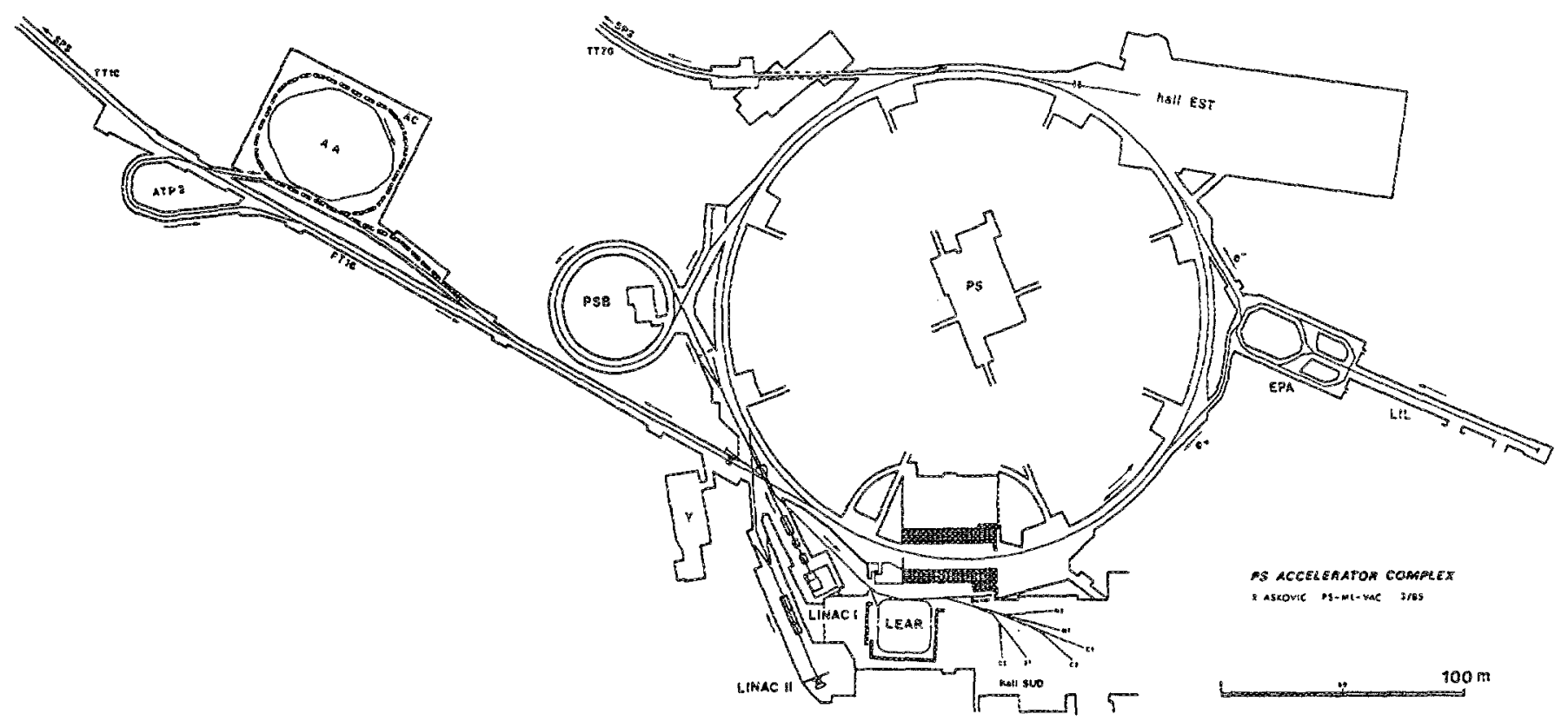

FIG. 1. PS accelerator complex.

Other classical alternatives, which are usually offered to the designer, concern the choice between fixed or mobile roughing stations, and the use of individual or common high-voltage power supplies for sputter ion pumps. Experi- ence, based on the operation of a large number of vacuum systems around the PS accelerators complex, has proven that mobile roughing carts are not desirable: arguments such as rapidity of intervention, ease of operation, versatility, and
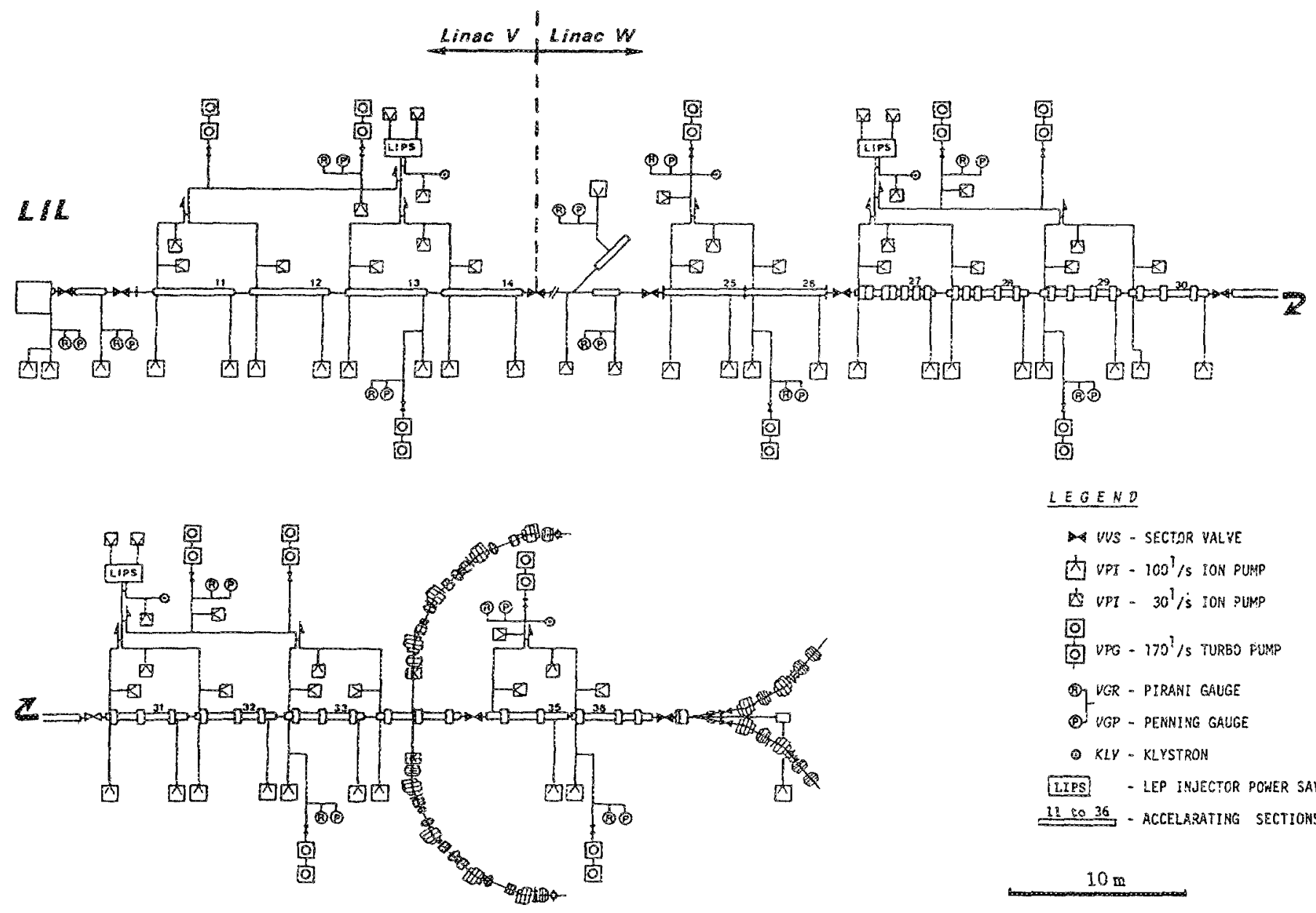

LEGEND

WUS - SECTDR VALiE

A UPS $-100^{\prime} / \mathrm{s}$ ION PUAPP

C $\mathrm{VPI}-30^{\mathrm{i}} / \mathrm{s}$ ION PUMP

(a)

商 UPG - $170^{\mathrm{l}} / \mathrm{s}$ TUREO FUMP

60) VGR - PIRRAI GRUGE

(10) VGP - PENNING GAUGE

- KLY - KLYSTRON

LIPS - LEP INJECTOR POUNER SAVER 318036 - ACCELARATING SECTIONS

Fio. 2. LIL vacuum system layout. 
as short as possible down times usually dominate over the small economic differences between mobile and fixed roughing stations. These same arguments prevailed when a combination of good-quality (high compression ratio) turbo and two-stage rotary vane pumps with all necessary built-in interlocks was preferred to sorption pumps. Continuous progress in industry triggered by extended markets, allows one to select high-quality standard turbopump stations at relatively low prices. Detailed consideration of the possibility to power several sputter ion pumps in parallel from one power supply led-in the LIL and EPA case--to the conclusion that individual powering had all the advantages: technically with adequate overall redundancy or safety margin in case of failures, and cconomically also when one considers the necessity to retain individual overcurrent pump protection and pressure reading. High-voltage power supplies with low leakage current and all the necessary protection circuitry were obtained at a very low price from industry through competitive tendering.

Equally important is the specification for vacuum couplings, component construction, cleaning, and thermal treatments in order to ensure the specified low outgassing rates. The LIL vacuum systems employ all-metal sector valves, quick disconnect Pneurop couplings of various sizes with aluminum seals, and copper-gasket flanges. As a general rule all finished aluminum, copper, and stainless-steel components have been cleaned to UHV standaris and finally prebaked or vacuum fired (stainless steel) prior to installation. The copper waveguide components were brazed, after thorough cleaning, to newly designed stainless-steel flanges at $780^{\circ} \mathrm{C}$ in a vacuum oven, using a silver-copper eutectic. This led to an unstable fully annealed state, and in order to reestablish mechanical stability and strength without impairing the low outgassing rate obtained from the vacuum brazing, all components were cold worked by internal pressurization using pure nitrogen, followed by externai mechanical squeezing to the original shape and dimensions.

Reliable stainless-steel rectangular fianges for the waveguides were optimized through finite element calculation and extensive field testing. After cleaning, the disk loaded accelerating cavities, made of a fine grain pure oxygen-free high-conductivity (OFHC) copper, were bonded together by silver diffusion at $350^{\circ} \mathrm{C}$ in a specially built $7-\mathrm{m}$-long vacuum oven, having a low base pressure of $10^{-6}$ mbar. This ensured a hydrocarbon-free prebake of the structures prior to fitting inside their stainless-steel heavy gauge tube envelopes.

\section{THE ELECTRON POSITRON ACCUMULATOR VACUUM SYSTEM}

The pulses of electrons and positrons delivered by LIL are accumulated in sequential periods of 1 to $12 \mathrm{~s}$ in the 600 $\mathrm{MeV}$ storage ring EPA where they are radiation-damped prior to further injection in the PS machine (Fig. 3). Considerations of particle lifetime against coulomb scattering by the residual gas ${ }^{3}$ lead to an operating design pressure of less than $10^{-8}$ mbar with low mass species in presence of synchrotron radiation induced gas desorption. Although not baked in situ, the 126-m vacuum chamber and the usual ingredients such as injection-ejection kickers, rf cavity, and beam sensing equipments have been built according to UHV

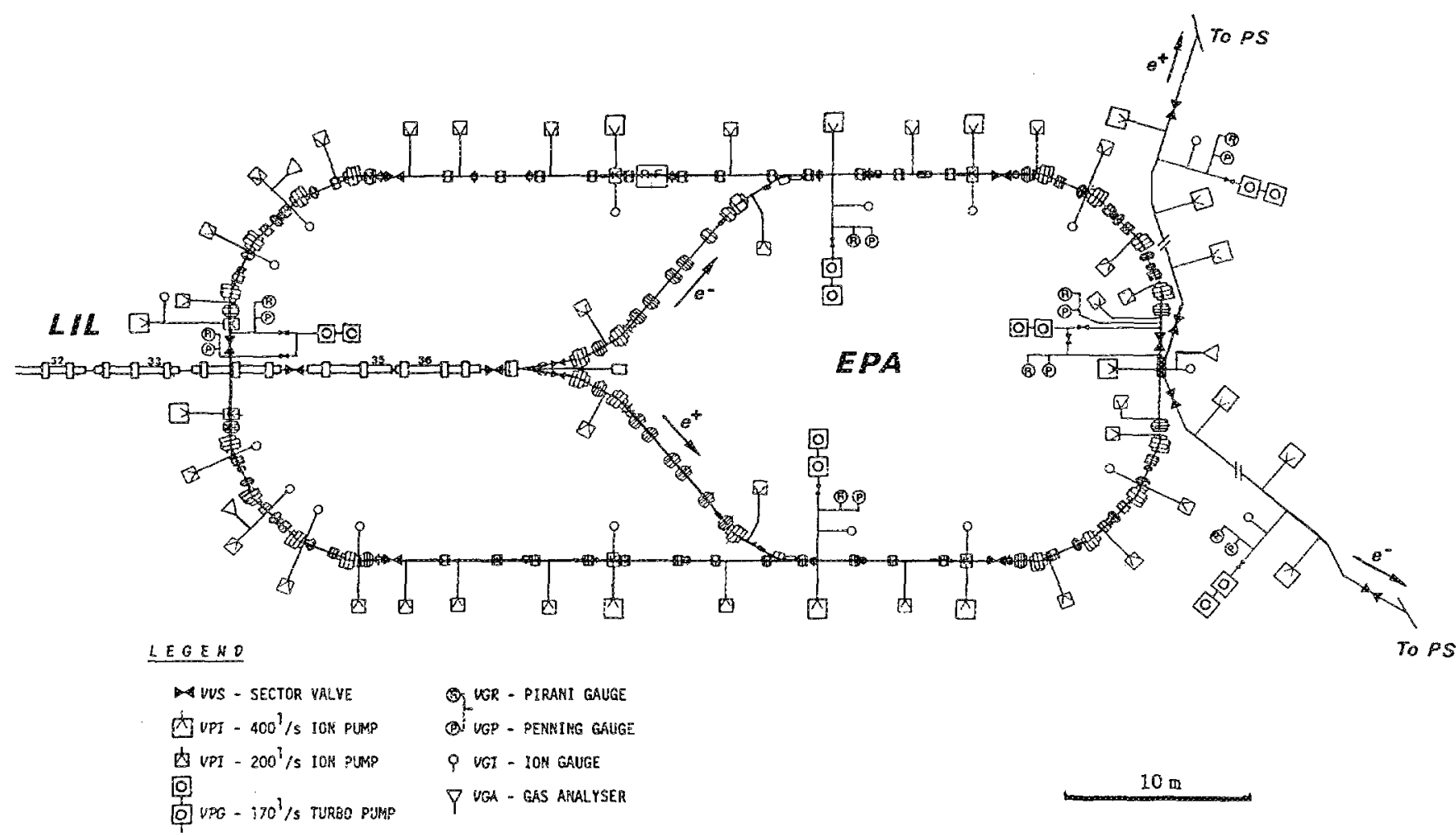

FiG. 3. EPA vacuum system layout. 
specifications. The vacuum chamber is made of refined AISI 316 austenitic stainless steel alloyed with nitrogen, in preference to aluminum alloys, both because it can be better welded and assembled into standard flanged parts and also because the low thermal power generated by synchrotron radiation does not necessitate a high thermal conductivity. According to a practice now common at CERN, most of the finished chambers and components have been vacuum fired at $950^{\circ} \mathrm{C}$ for $2 \mathrm{~h}$ at a pressure less than $10^{-4} \mathrm{mbar}$, as a last treatment following a thorough chenical cleaning sequence. High-temperature vacuum firing is known to be a bulk degassing treatment commonly used for bakable in situ vacuum systems. It is our experience that it is also worth applying to unbaked systems in order to further reduce surface contamination. Outgassing rates as low as a few $10^{-12}$ mbar $1 \mathrm{~s}^{-1} \mathrm{~cm}^{-2}$ can thus be achieved after several days of pumping on a large unbaked system ${ }^{4}$ with less than $50 \%$ of water in the residual gas. A further advantage of this vacuum firing treatment is that it gives low molecular yields under ion or electron impact, even after long periods of air exposure. This is of particular interest on electron-positron machines like EPA where the dynamic gas load due to desorption by the photoelectrons generated by the synchrotron radiation is high. During the design period of EPA, studies of photon induced gas desorption using the synchrotron radiation produced by the DCl storage ring, and $x$ rays from a lamp source, were conducted in order to check on the consequences that electron-positron acceleration would have on the PS vacuum system. ${ }^{5}$ This, together with proper scaling of data from existing electron machines ${ }^{6}$ led to estimates of the molecular yield per impinging photon ( $\eta$ ) as a function of the dose received ( $D$ : the integral of the electron current versus time in $\mathrm{MA} h$ ) for the EPA case:

$$
\eta=10 \wedge[-0.44 \log (D)-3.22]
$$

from which the dynamic gas load could be calculated and the pumping system designed. It was thus found that a cleanedto-UHV standards all-stainless-steel chamber, vacuum fired to $950^{\circ} \mathrm{C}$ prior to installation, could be pumped with a reasonable amount of standard lumped $200 \mathrm{l} / \mathrm{s}$ triode sputterion pumps placed near to the bending magnets where the highest dynamic gas load is expected, and the required average pressure obtained in a reasonable delay. Low beam-impedance clearing electrodes are installed at each pump location, designed to extract the positive ions created and trapped by the electron beam. In order to minimize a possible lengthy process of chamber beams reconditioning after exposure to air, the 126 -m-long machine is divided into six sectors isolated by all metal valves: four short sectors $(\sim 11$ m) with bending magnets and two long straight sectors $(\sim 42 \mathrm{~m})$ with beam injection equipment. Pairs of short sec tors are equipped with one common fixed turbomolecular pumping station which can be switched to either one-or both sectors-for initial roughing down via a common manifold comprising pneumatically controlled Viton sealed right-angle valves; each long sector is roughed down by one fixed pumping group.

Pressure monitoring is ensured by the usual cascade of commercial Pirani-Penning gauges (down to $10^{-7} \mathrm{mbar}$ ), ion pump current reading $\left(10^{-5}-10^{-8}\right.$ mbar $)$, and $16 \mathrm{Ba}$ yard-Alpert hot filament ion gauges $\left(10^{-7}-10^{-10} \mathrm{mbar}\right)$. Three quadrupole-type residual gas analyzers are used to record partial pressures. Early at the design stage it was decided to privilege two short bending pilot sectors, each

TABLE I. LIL anú EPA main vacuum parameters.

\begin{tabular}{|c|c|c|c|c|c|c|c|c|c|}
\hline \multicolumn{7}{|c|}{ Design } & \multicolumn{3}{|c|}{ Initial performance } \\
\hline & $\begin{array}{l}\text { Length } \\
\text { (m) }\end{array}$ & $\begin{array}{c}\text { Design base } \\
\text { pressure } \\
\text { (mbar) }\end{array}$ & $\begin{array}{l}\text { Max. oper. } \\
\text { pressure } \\
\text { (mbar) }\end{array}$ & $\begin{array}{c}\text { Conductance } \\
\text { for air } \\
(1 \mathrm{~m} / \mathrm{s})\end{array}$ & $\begin{array}{l}\text { Ion pump } \\
\text { nom. speed } \\
(1 / \mathrm{s})\end{array}$ & $\begin{array}{l}\text { Interval } \\
\text { between } \\
\text { pumps }(\mathrm{m})\end{array}$ & $\begin{array}{l}\text { Pumping time } \\
\text { to achieve base } \\
\text { pressure (days) }\end{array}$ & $\begin{array}{c}\mathrm{LIL} \\
D P / P O^{\mathrm{a}}\end{array}$ & $\begin{array}{c}\text { EPA } \\
D P / D I \\
(\mathrm{mbar} / \mathrm{mA})^{b}\end{array}$ \\
\hline $\begin{array}{l}\text { LIL if } \\
\text { waveguides }\end{array}$ & 350 & $<10^{-8}$ & $5 \times 10^{-7}$ & 20 & 30 & 11 & 7 & $50 \%$ & \\
\hline $\begin{array}{l}\text { LIL if } \\
\text { sections }\end{array}$ & 100 & $<5 \times 10^{-8}$ & $5 \times 10^{-7}$ & 30 & 100 & 6 & $<7$ & $50 \%$ & $1 \times 10^{-13 k}$ \\
\hline EPA & 126 & $<5 \times 10^{\circ}$ & $1 \times 10^{8}$ & 35 & 200 & 3 & $<5$ & & $\begin{array}{l}\mathrm{H}_{2}: \\
2.5 \times 10^{-16 \mathrm{~d}} \\
1.8 \times 10^{-100} \\
\mathrm{CO}: \\
6 \times 10^{-11 d} \\
2.5 \times 10^{-11 \mathrm{e}} \\
\mathrm{CO}_{2}, \mathrm{CH}_{4}, \mathrm{H}_{2} \mathrm{O}: \\
5 \times 10^{-12 d} \\
<10 \quad 13 \mathrm{e}\end{array}$ \\
\hline
\end{tabular}

\footnotetext{
${ }^{a}$ Relative operating pressure increase with 28 -MW, $1-\mu$ s rf puises at $100 \mathrm{Kz}$ (LIL).

${ }^{b}$ Specific pressure increase at $500 \mathrm{MeV}$ per $\mathrm{mA}$ of beam current at $78 \mathrm{~mA}$ (EPA) for main gases after $1 \mathrm{~mA}$ h of beam dose (critical energy $=200$ ) eV, radiated power $=0.8 \mathrm{~W} /(\mathrm{m} \mathrm{mA})$.

'Gauge machine average.

'Vac fired bending are.

-AGDC bending arc.

'EPA average bending arc pressure has decreased by a factor of 10 for initial $1 \mathrm{~A}$ h of beam dose.
} 
equipped with four ion gauges and one residual gas analyzer, in order to monitor precisely the dynamic pressure rise and surface cleaning process. One sector has been simply vacuum fired like the rest of the machine, while the other was additionally cleaned by glow discharge of a mixture of argon plus $10 \%$ oxygen [argon glow discharge cleaning ( $A G D C)]$, in order to assess the respective merits of these two treatments. It is well known from previous experience of the AGDC treatment, which was successfully applied on the ISR machine, ${ }^{7}$ that implanted argon can subsequently desorb in the system unless one performs a $350^{\circ} \mathrm{C}$ bakeout under vacuum following the discharge. The EPA chambers, equipped with newly designed quick disconnect DN 100 flanges with diamond shape aluminum seals, are not bakable to this temperature. Therefore, the AGDC treatment was applied in a UHV tank bakable at $350^{\circ} \mathrm{C}$ on batches of chambers each equipped with an anode wire which could be alternatively powered. After flling with pure nitrogen, these chambers were then welded inside their magnet, sealed, and stored for periods of several weeks before installation. EPA has 16 short dipole magnets ( $\sim 0.5 \mathrm{~m}$ long), with low bending radius $(-1.4 \mathrm{~m})$, such that the photon flux of synchrotron radiation is concentrated on a short length $(\sim 1 \mathrm{~m})$ of the vacuum chamber, where the pumping speed of the vacuum system is located ( $200 \mathrm{l} / \mathrm{s}$ triode sputter-ion pumps). For that reason the dynamic performance of the vacuum system can be assessed in first approximation assuming concentrated gas loads and pumping speeds.

Computer calculations of pressure profile and extensive laboratory measurements of pumping speeds and conductances for common gas $\left(\mathrm{H}_{2}, \mathrm{~N}_{2}, \mathrm{CO}, \mathrm{CH}_{4}, \mathrm{CO}_{2}\right.$ ) provided the necessary parameters for an educated performance guess. 8

Table I summarizes some of the relevant vacuum parameters.

\section{CONTROLS (LIL AND EPA)}

Controls of the vacuum systems of LIL and EPA are identical in nature and include simple standard features of other PS accelerator vacuum systems: individual equipments such as ion pumps and gauges are self-protected at the level of their power supplies. Turbopumping stations have their own protective interlock chain, while the high-vacuum valves are interlocked to the pressure indicated by Pirani-Penning gauges. Sector valve control is submitted to permit status from Pirani-Penning heads and ion pumps and receive external interlocks (valve open with beam "on" for instance). Power supplies for ion pumps and Bayard-Alpert gauges are of a new cheap design and have been built under competitive tendering by industry. All the vacuum equipment such as valves, pumps, and gauges can be controlled locally or from: remote equipment housing racks. The machine computer is provided with status acquisition and control of valves and pumps, pressure reading from ion pumps and gauges, via a standard serial Camac link. In addition a mobile trolley comprising a MacIntosh ${ }^{\mathrm{TM}}$ microcomputer linked to a Camac rate is used as a versatile data acquisition system, capable of recording and interpreting residual mass spectra and monitoring the conditioning of the EPA vacuum chamber.
Excluding the vacuum chambers, waveguides, and supports, the total cost of the LIL and EPA vacuum systems has been 1.82 million Swiss francs including installation, of which $50 \%$ was for power supplies and controls. About $16000 \mathrm{H} / \mathrm{s}$ of sputter-ion pumping speed were installed, thus giving an average price of 11 Swiss francs per $1 / \mathrm{s}$ of pumping speed, allowing an operating average pressure of less than $10^{\cdots 8}$ mbar to be maintained in these machines.

\section{INITIAL PERFORMANCE (LIL. AND EPA)}

Final commissioning of the various systems occurred during the spring of 1986 and the machines are currently in a running-in stage with electrons at $500-\mathrm{MeV}$ operating energy. An average pressure of less than $10^{-7}$ mbar in the linacs is obtained in less than two days of pumping. Apart from the LEP injector power saver (LIPS) cavities for which rf conditioning is more tedious due to the high rf peak power (100 $\mathrm{MW}$, the $600-\mathrm{MeV}$ linac sections and waveguides have run without problems and experience initial rf induced gas loads of only $1.5-2 \times$ the static ones with near to the nominal of power.

Initial pumpdowns of the EPA damping ring have confirmed the remarkable cleanliness of the vacuum system. An average base pressure of less than $10^{\cdots 8}$ mbar is reached in less than two days of pumping, and after a week $10^{-9} \mathrm{mbar}$ is obtained with hydrogen representing more than $70 \%$ of the residual gas (yielding an overall average outgassing rate of less than $10^{-11}$ mbar $1 \mathrm{~s}^{-1} \mathrm{~cm}^{-2}$ without bakeout). After a month of running in at $500 \mathrm{MeV}$ with electron beams of up to $200 \mathrm{~mA}$-representing more than three times the nominal

(a)
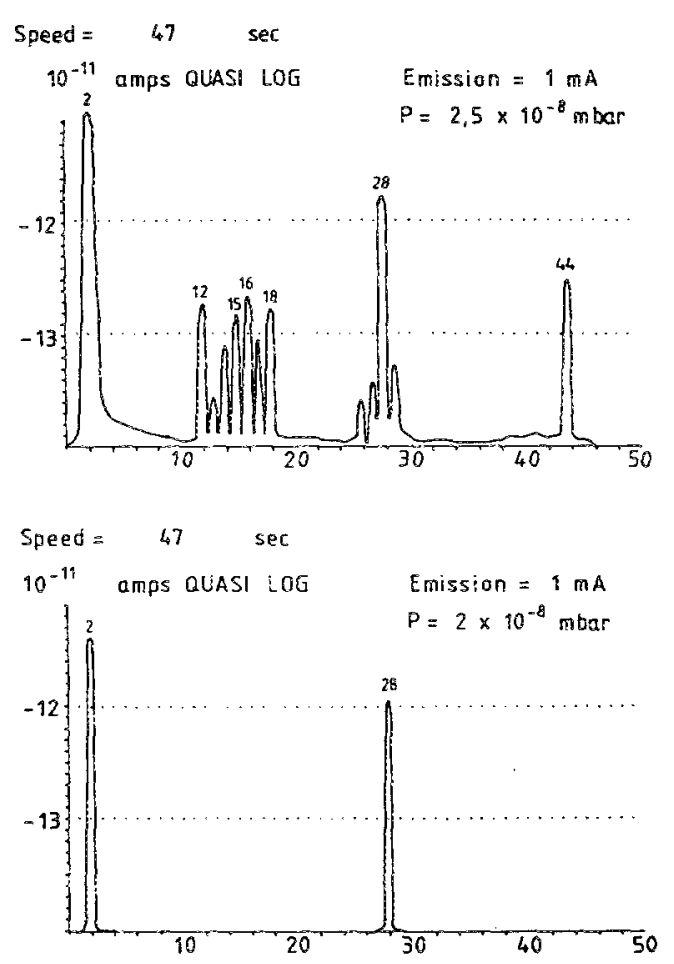

(b)

FIG. 4. (a) The residual gas spectrum in the vacuum fired pilot sector of EPA after $0.5 \mathrm{~A} \mathrm{~h}$ of beam dose and $65 \mathrm{~mA}$ of circulating current. (b) The residual gas spectrum in the argon glow discharged sector under the same conditions. 
value-an operating average pressure of less than $10^{-\frac{8}{8}} \mathrm{mbar}$ was obtained at $80 \mathrm{~mA}$, giving a beam lifetime of more than 20 min which is more than adequate. Table I summarizes the behavior of the system in presence of synchrotron induced gas desorption.

Finally, detailed analysis of the initial cleaning process has already shown the seemingly superior behavior of the pilot sector cleaned by argon glow discharge (Fig. 4). Not only is the dynamic overall specific pressure rise lower by $50 \%$, but the photon induced desorption of $\mathrm{CO}, \mathrm{CO}_{2}$, and $\mathrm{CH}_{4}$ is more than an order of magnitude lower than in other merely vacuum fired but otherwise identical sectors.

${ }^{1}$ LEP Study Group, CERN Internal Report No. CERN-LEP/TH/83-29, 1983.

${ }^{2}$ H. F. Malthouse, CERN Internal Note Nio. PS/ML/Note 82-18, 1982.

${ }^{3}$ A. Poncet, CERN Internal Note No. PS/ML/Note 83-3, 1983.

${ }^{4}$ M. Brouet, M. Chanel, A. Poncet, and P. L. Riboni, CER Internal Report No. CERN/PS/ML/83-42, 1983.

${ }^{5}$ A. Poncet, CERN Internal Note No. PS/ML/Note 84-8, 1984.

6O. Gröbner, CERN Internal Note No. ISR-VA/OG/sm/tn-4, 1982

'E. Fischer, J. Vac. Sci. Technol. 9, 1203 (1972).

${ }^{8}$ A. Poncet, CERN Internal Note No. PS/ML/Note 85-1, 1985. 